\title{
Systemic lupus erythematosus presenting with cardiac tamponade
}

\author{
NADINE CARROLL, JAMES A BARRETT* \\ From the Royal Liverpool Hospital, Liverpool
}

SUMMARY A previously well 36 year old man presented with cardiac tamponade as the initial manifestation of systemic lupus erythematosus. This diagnosis should, therefore, be considered not only in cases of pericarditis but also in those of tamponade.

\section{Case report}

A 36 year old man was admitted as an emergency with a six week history of increasing peripheral oedema and dyspnoea and a three month history of general malaise. He had no notable past illnesses and was an unemployed oil rig worker, living alone and eating a very poor diet. On questioning he complained of no other symptoms referrable to the cardiovascular or respiratory systems.

On examination he was unwell, with a pyrexia of $38^{\circ} \mathrm{C}$ and dyspnoea at rest. He had pitting oedema up to the mid-calf, jugular venous engorgement which increased on inspiration, a tachycardia of 120 beats/ $\mathrm{min}$, and a blood pressure of $100 / 70 \mathrm{~mm} \mathrm{Hg}$ with a paradox of $25 \mathrm{~mm} \mathrm{Hg}$. His apex beat was impalpable; there was a gallop rhythm and mild hepatomegaly. There was no pericardial friction.

A chest radiograph showed cardiomegaly, and an electrocardiogram a sinus tachycardia with low voltage complexes, electrical alternans, and ST segment elevation suggesting pericarditis. The diagnosis of pericardial effusion causing cardiac tamponade was confirmed by ultrasound examination of the heart. Pericardiocentesis using the xiphoid approach allowed aspiration of $500 \mathrm{ml}$ of straw coloured fluid, and during this procedure the physical signs of tamponade disappeared and a pericardial friction rub became apparent. The pericardial fluid was found to be an exudate containing many polymorphonuclear leucocytes but no organisms, and Ziehl-Neelsen stains were negative. Multiple blood cultures and a tuberculin

^Present address: Arrowe Park Hospital, Wirral, Merseyside.

Requests for reprints to Dr N Carroll, (Link Unit 5Z), Royal Liverpool Hospital, Liverpool L7. skin prick test were also negative.

After the pericardiocentesis treatment was begun with intravenous benzyl penicillin, but the patient remained pyrexial throughout the 10 days of this treatment. On the tenth day after admission tests for antinuclear antibody were reported as strongly positive (titre 1/1024). Deoxyribonucleic acid binding was $80 \%$ and the presence of LE cells confirmed the diagnosis of systemic lupus erythematosus.

Prednisolone $60 \mathrm{mg}$ daily was given, and within 24 hours the pyrexia had resolved and the friction rub disappeared. After two weeks' treatment the heart size had returned to normal on the chest radiograph, and the electrocardiogram showed no abnormalities. The patient has since been followed up on several occasions, and his dose of prednisolone reduced to 10 $\mathrm{mg}$ on alternate days. He remains well and has no symptoms or signs of active disease.

\section{Discussion}

The cardiac manifestations of systemic lupus erythematosus are well known. Pericarditis is the most frequent cardiac manifestation, but pericardial tamponade has rarely been reported. In Dubois's study of 520 cases pericarditis was the presenting symptom on admission, and systemic lupus erythematosus was diagnosed in only $13(2.5 \%)$ cases. ${ }^{1}$ Pericarditis is found at various stages during the course of the disease in a much larger percentage; $31 \%$ of 83 patients reported by Shearn in 1959 had pericarditis. ${ }^{2}$

Cardiac tamponade as the only initial manifestation of systemic lupus erythematosus is rarely seen and has been reported on only four previous occasions, all in American women. Two of the previously reported cases were of drug induced lupus-one induced by 
hydralazine ${ }^{3}$ in a 62 year old woman and the other by procainamide ${ }^{4}$ in a 75 year old woman. Both patients required emergency pericardiocentesis. The other two cases were of a 15 year old black girl, 5 who required pericardiocentesis because of a rapidly developing tamponade, and of a 24 year old Puerto Rican woman, ${ }^{6}$ who required pericardial fenestration and insertion of drainage tubes. After pericardiocentesis all four patients required high doses of prednisolone and made a good recovery without any recurrence of the signs of tamponade.

It has been suggested ${ }^{7}$ that once the diagnosis of systemic lupus erythematosus is established systemic corticosteroids will rapidly reduce the symptoms and signs of cardiac tamponade, thus obviating the need for pericardiocentesis. In all four previously recorded cases, however, the situation was an emergency and the risks of pericardiocentesis ${ }^{8}$ were considered to be far outweighed by those of the tamponade induced by a large effusion.

This is the first case in Britain of systemic lupus erythematosus presenting with cardiac tamponade and is the first male case in the world. The case emphasises the need to consider the diagnosis of systemic lupus not only in cases of pericarditis but also in those of tamponade.
We thank Dr C C Evans for permission to report this case.

\section{References}

1 Dubois EL. The clinical picture of systemic lupus erythematosus. In: Dubois EL, ed. Lupus erythematosus. New York: McGraw-Hill, 1966: 151.

2 Shearn MA. The heart in systemic lupus erythematosus. Am Heart f 1959; 58: 452-66.

3 Carey RM, Coleman M, Feder A. Pericardial tamponade: a major presenting manifestation of hydralazine-induced lupus syndrome. Am $\mathcal{F}$ Med 1973; 54: 84-7.

4 Ghose MK. Pericardial tamponade. A presenting manifestation of procainamide-induced lupus erythematosus. Am $\mathcal{~ M e d ~ 1 9 7 5 ; ~ 5 8 : ~ 5 8 1 - 5 . ~}$

5 Lerer RJ. Cardiac tamponade as an initial finding in systemic lupus erythematosus. Am $\mathcal{F}$ Dis Child 1972; 124: 436-7.

6 Goldenberg DL, Leff G, Grayzel AI. Pericardial tamponade in systemic lupus erythematosus: with absent hemolytic complement activity in pericardial fluid. $N Y$ State $\mathcal{F}$ Med 1975; 75: 910-2.

7 Dubois EL. The clinical picture of systemic lupus erythematosus. In: Dubois EL, ed. Lupus erythematosus. New York: McGraw-Hill, 1966: 164.

8 Krikorian JD, Hancock EW. Pericardiocentesis. Am 7 Med 1978; 65: 808-14. 